\title{
Scrutinizing local public service provision
}

\section{Anna Coleman, Francesca Gains, Alan Boyd, Donna Bradshaw and Carole Johnson}

Set in the context of an expansion of scrutiny by local authorities of local service provision, this article explores the key challenges ahead for managers and politicians in this area of local governance. Drawing on an evaluation of the development of health scrutiny, it outlines the different types of activities health scrutiny committees are engaging in to fulfil their legislative commitments and suggests lessons for the expansion of external scrutiny.

New Labour's Local Government Modernization Agenda (LGMA) sought improvement in the delivery of public services through strengthened leadership structures and partnership working (DETR, 1998). However, these developments create potential problems associated with accountability, transparency and openness (Sullivan and Skelcher, 2003). The introduction of local authority scrutiny through the Local Government Act 2000 aimed to provide a counterbalance to strengthened executive power and ensure responsiveness of local decision-makers to elected representatives and the public.

The Local Government and Public Involvement in Health Act 2007 provides the next steps in the government's modernization agenda. Building on the policy framework set out in the white papers Strong and Prosperous Communities (DCLG, 2006) and Our Health, Our Care, Our Say (Department of Health, 2006a), the Act includes further measures to strengthen leadership, encourage partnership working, community empowerment and introduce more accountable public service delivery. Part 5 of the Act introduces a strengthening of the powers of local overview and scrutiny committees both in utilizing new 'councillor calls for action' to examine issues around internal services but also a greater external scrutiny role of other key local public service providers. The white paper Communities in Control (DCLG, 2008) further promises to raise the visibility of the scrutiny function and encourage new approaches to scrutiny. In responding to this expanding external scrutiny agenda local authorities will build on their experiences of health scrutiny.

Health scrutiny (Department of Health,
2003), as the earliest form of statutory external scrutiny, is an ideal test-bed for issues that may arise as scrutiny is rolled out to provide oversight of a wider range of public services. This article explores these issues using the findings from a three-year health scrutiny evaluation research project, in England, carried out by the University of Manchester, commissioned by the Centre for Public Scrutiny (CfPS). The full report of this research discusses the democratic accountability functions fulfilled by health scrutiny and looks in detail at the effectiveness of health scrutiny (CfPS, 2007; Johnson et al., 2007). Here we highlight the key factors involved in scrutinizing external bodies. We also examine the tensions which exist for local authority actors in conducting challenges to providers and campaigning on issues of local service provision at the same time as seeking to work in collaboration with local partnerships and develop corporate strategies.

\section{The development of external scrutiny in local governance}

The modernization of UK local public services during the past 10 years stemmed from a desire to strengthen executive leadership to deliver better management of services, while at the same time enhancing accountability and encouraging greater public involvement (DETR, 1998). The Local Government Act 2000 split the decision-making and oversight roles of local councillors. The scrutiny role of non-executive councillors was introduced to challenge, as a 'critical friend', the decisions taken by the smaller group of elected executive councillors in order to provide a check and balance to new executive powers and to improve the delivery of public services (Ashworth and Snape, 2005; CfPS, 2006, Stoker et al., 2007).
Anna Coleman is a research fellow in the National Primary Care Research and Development Centre (NPCRDC),

University of Manchester.

Francesca Gains is a senior lecturer in the School of Social Sciences, University of Manchester.

Donna Bradshaw is a founder and director of Organisation Development Services (ODS), Manchester.

Alan Boyd is a research associate at the Manchester Business School.

Carole Johnson is lecturer in public policy and management and fellow of the Herbert Simon Institute, Manchester Business School. 
For the elected councillors who are members of scrutiny committees, and their supporting officers, this was a significant new role (Stoker et al., 2004). The newly-created local authority overview and scrutiny committees had five main functions (Snape and Taylor, 2001; Snape and Dodds, 2003):

- Holding the executive to account.

- Policy review.

-Policy development.

- Best value reviews.

-External scrutiny.

There were high hopes that scrutiny would make an impact and Coleman (2006, p. 126) suggested that the process had the potential to: 'contribute to the community leadership role of local authorities, help tackle cross-cutting issues (for example health inequalities, crime reduction) and stimulate a more reflexive and evidence based culture with meaningful public involvement'. However, Leach's (2005, p. 3) view was less positive:

...overview and scrutiny was the most unfamiliar element in the range of structures introduced by the Local Government Act 2000...it is not surprising, therefore, that of all the elements...it is overview and scrutiny which has struggled most to make an impact.

An evaluation of the Act by Stoker et al. (2007) concluded both that scrutiny had had an impact but also that the scrutiny role had embedded less successfully than the new executive arrangements.

The external role of scrutiny was initially directed towards the scrutiny of health through a series of legislative measures which came into force in 2003 (see figure 1). Since then, uppertier authorities have been required to maintain an overview and scrutiny committee (OSC), composed of elected non-executive councillors, who can respond to proposals from the National Health Service (NHS) to changes in services and has the discretion to set their own agendas for undertaking more detailed scrutiny of health issues (including the NHS). These committees may be standalone (health focus), or combined with scrutiny of other services (for example social services), and are supported by local authority officers (dedicated scrutiny role or combined with a service role) and have evolved differently around England (Coleman and Harrison, 2006).

Health scrutiny had the twin aims of acting as a lever on NHS bodies and local authorities in order to improve the health of local people.
Therefore it required scrutiny committees to support the corporate agenda of these bodies, as well as pointing to both a campaigning and sometimes challenge role for scrutiny. Additionally, health scrutiny built on other key themes and issues that have long been apparent within the NHS and local government. These included an emphasis on developing closer collaborative relationships between health and social care, involving local councillors on various health bodies and requiring the NHS to be more accountable to the public (Glasby and Smith, 2003). Health OSCs (HOSCs) were one element of the patient and public involvement structures introduced as community health councils (CHCs) were abolished during 2003 (Coleman and Glendinning, 2004) which ensured maintenance of a consultation role regarding major changes to service provision. HOSCs were expected to engage in corporate, collaborative, challenge and campaigning directed activities in order to fulfil the legislative requirements set out in figure 1 .

During 2006, three major publications were released which signalled developments in the future direction of health scrutiny and the expansion of external scrutiny in other areas. Our Health, Our Care, Our Say (Department of Health, 2006a), flagged an expansion of 'community calls for action' (CCfA) where elected local councillors act as advocates for their local communities. A Stronger Local Voice (Department of Health, 2006b) suggested the establishment of local involvement networks (LINks), to replace patient and public involvement forums (PPIFs), co-terminous with local authority boundaries, to help facilitate joint working. It also proposed that HOSCs were to be encouraged to focus on commissioning processes. Finally, Strong and Prosperous Communities (DCLG, 2006), suggested extending scrutiny's remit to other service providers, a role for CCfA, encouragement of area OSCs and a more strategic focus on Local Area Agreements (LAAs).

The Local Government and Public Involvement in Health Act 2007 gives legislative intent to these policy ideas. The Act uses a more tightly defined framework which introduces single 'councillor calls for action' (enabling any member of the council to refer to an OSC, a local government matter which falls within the committee's remit), wider scrutiny powers limited to include those bodies under a duty to agree targets for the LAA, and powers to request information (not attendance) in relation to LAA targets.

This legislation suggests a strong message 
from government in terms of involving and responding to the demands of local populations. There is also a shift in the interpretation of overview and scrutiny from initial network building to a greater focus on external scrutiny and challenge through the introduction of councillor calls for action. This stronger challenge function is taking place at a time when the collaboration between local authorities and other local public service providers will be made more formal and extensive with the introduction of LAAs. The experience of the adoption of health scrutiny provides valuable insights here for local public service managers on the challenges these changes may produce and how they may be overcome.

\section{Research methodology and design}

The data presented evolves from the qualitative element of a programme of research, funded by the CfPS, evaluating the development of health scrutiny from 2004 to 2007 . Eight sites (local authorities and their associated health bodies) were chosen using information gained from quantitative postal surveys of local authorities (Coleman, 2005) and NHS organizations (Bradshaw et al., 2005) to reflect diversity of local authority structures and provide a range of sites with different approaches to and at different stages of the development of health scrutiny. Data was collected through interviews, observation and analysis of available associated documentation (agendas, minutes, reports, evidence submissions etc.). Comparing data from interviews with data collected in observations (formal and informal public and private meetings associated with health scrutiny) allowed a more comprehensive understanding of the health scrutiny process than could have been achieved from using one method alone. Observations of scrutiny committee activity over a 15-month period were recorded in the form of detailed field notes and over 60 interviews (face-to-face and telephone) were conducted across the eight sites. Respondents varied across the sites but included local authority scrutiny and service officers, councillors (non-executive and executive) and representatives from the associated NHS bodies, for example NHS trusts and primary care trusts (PCTs). Emerging themes and theoretical issues were discussed within the research team and with the associated academic reference panel throughout the research period to ensure consistency.

\section{The development of health scrutiny}

The interviews with elected councillors and officers from local authorities and the NHS explored key factors thought to have impacted on the adoption and operation of health scrutiny work (see table 1). Respondents discussed external, structural, contextual and internal issues. While differences between the sites, in terms of the development of health scrutiny, could be identified, data reported on the key factors affecting its development were consistent across the sites leading us to suggest there are transferable lessons for the expansion of external scrutiny.

Key external factors affecting the development of health scrutiny

External factors such as the policy from central

\section{Figure 1. Legislation around health scrutiny (adapted from Coleman, 2003).}

Local Government Act 2000

- Created the executive/scrutiny split in the governance of local authorities.

- Gave local authorities the power to promote 'economic, social and environmental wellbeing' of communities.

- Gave local government the duty to prepare community strategies.

Health and Social Care Act 2001

- Conferred on local authorities with social service responsibilities the role of reviewing and scrutinizing health service matters.

- Gave health overview and scrutiny committees (OSCs) powers to delegate health scrutiny to other authorities, including districts, or to carry out joint scrutiny.

- Placed duties on health trusts to consult health OSCs about major changes to services.

- Required officers of health trusts to attend health OSCs when requested.

- Required NHS bodies to respond to reports and recommendations from health OSCs.

NHS Reform and Health Care Professions Act 2002

- Abolished community health councils in England.

- Created patients' forums for each PCT and NHS trust.

- Gave powers to patients' forums to refer to health OSCs.

- Created the Commission for Patient and Public Involvement in Health.

- Gave local authority health OSCs power to refer contested NHS proposals to the secretary of state for health. 
Table 1. Factors and indicators impacting upon the development of health scrutiny emerging from interview data (Bradshaw et al., 2005).

\begin{tabular}{|c|c|}
\hline Factor & Indicators \\
\hline External factors & $\begin{array}{l}\text { Significant developments and variations to service (SDVs) from NHS consultations } \\
\text { (numbers and complexity) } \\
\text { Public awareness/involvement } \\
\text { Other policy initiatives } \\
\text { Specific local factors } \\
\text { History of relations with the NHS } \\
\text { Importance of individual relationships }\end{array}$ \\
\hline Structural factors & $\begin{array}{l}\text { OSC structure (where does health scrutiny sit?) } \\
\text { Statutory joint committees } \\
\text { Numbers of boundaries (health/local authority) } \\
\text { One-tier/two-tier local authority }\end{array}$ \\
\hline Context factors & $\begin{array}{l}\text { Strategic context } \\
\text { Policy context } \\
\text { Particular local/regional agendas } \\
\text { Particular local/regional political climate and history } \\
\text { Recent history and experiences of joint working } \\
\text { Boundary changes }\end{array}$ \\
\hline Internal factors & $\begin{array}{l}\text { Support/status of health scrutiny (and general scrutiny) } \\
\text { Importance of Chairs of OSCs } \\
\text { Training (and resulting expertise of officers/councillors) for health scrutiny in general } \\
\text { Choice of work programme (decision-making mechanisms and types of topics) } \\
\text { Resources (time/finance/officer support) } \\
\text { OSC styles-approach (committee style, parliamentary select committee or new) } \\
\text { Monitoring and evaluation } \\
\text { Type of officer support (social services, independent scrutiny unit, dedicated officer for } \\
\text { health scrutiny, democratic services) } \\
\text { Use of co-options onto 'health' OSC and advisors/experts. }\end{array}$ \\
\hline
\end{tabular}

government to structurally reconfigure health service bodies (for example the reorganization of PCT boundaries in 2006, intended to improve co-terminosity between local authorities and PCTs and benefit joint working where all HOSCs in the sample were consulted on proposed changes), while not intending to be detrimental to the health scrutiny process, often constrained review activity, taking up valuable time and resources during periods of consultation. Additionally, the majority of the HOSCs contributed to the annual Health Check for the Healthcare Commission, which required a report from the HOSC about the health bodies to inform the wider review and had participated in reviews around substantial developments and variations to service (SDV) previously.

It was also apparent that greater collaboration, of the sort Local Area Agreements (LAAs) encourage, was thought to be necessary. However, despite stressing the need for a collaborative way of working, many respondents (NHS and local authority) also identified tensions due to different organizational targets and objectives for local authorities and NHS bodies set at a national level:

...just thinking in terms of the consultation, there is a tension financially, because money comes down different lines and in different priority directives, the guidance for instance about 'Our
Health, Our Care, Our Say' is much more community provided, community supported, it doesn't seem from the local authority's perspective to take account of the impact on them, and its this sort of 'joined up-ness' sometimes isn't helpful, the lack of joined up-ness (NHS officer).

Key structural factors affecting the development of health scrutiny

Structural factors also played a role in the way in which health scrutiny was adopted. For example, two-tier authorities generally cover a larger geographical area than a unitary and relate to district councils, as well as multiple NHS organizations (therefore boundaries of organizations may not match as well) potentially resulting in more complex relationships in the operation of health scrutiny. Among our cases, a single HOSC related to up to three primary care trusts and five NHS trusts. Each case was additionally involved with at least one joint health scrutiny committee having representation from more than one local authority health related committee.

HOSCs varied in structure, but in our sample were most commonly a dedicated health committee (five cases). The remaining three were combined with other related local authority service functions, such as adult social care. Dedicated HOSCs have the advantage of specialization, but may not as easily make the connections with local authority services. 
Key contextual factors affecting the development of health scrutiny

Contextual factors impact upon and help to create the wider political and strategic context within which local authorities and NHS bodies operate at a local and regional level. This includes political climate, historical context and specific local/regional agendas. Despite health scrutiny being conducted in a political environment, local politics only adversely affected one case during the research period:

I think all the members are keen to make a change and improve the way local health services are provided. When they go into their meetings they do work as a team, and party politics are left to one side...Scrutiny is all about that and, from what I've seen, members are keen and readily willing to do that (local authority officer).

The picture potentially becomes further complicated during a joint scrutiny exercise, however, where several local authority HOSCs are represented and all have differing ways of working:

I think we were very much not wanting to see a political steer on it...we want to see the best result, and what we perhaps didn't want to see was political steer, and I think initially we thought that it was quite political, because there was a little bit of shenanigans about how many members from each council and about balancing that out, well actually if you've got the three best people to do the job, fromeach council, doesitmatter? (councillor).

Key internal factors affecting the development of health scrutiny

Our research explored internal process factors in the greatest depth, these being the factors which are those that the local authority and NHS organizations involved in health scrutiny have a greater degree of control over. These factors include resourcing, officer support, and training. Officer support to health-related committees was commonly provided from specialized scrutiny units, but many suffered from a lack of resources (money, time, capacity), which constrained activity. Generally, chairs of HOSCs were councillors with some experience with the health sector (for example community health council member, PCT board member, social services member). Also seen as key internal factors were the type of scrutiny undertaken, the scrutiny approach, the agenda-setting process and actors involved. These key internal factors are discussed in the next section.

\section{The operation of health scrutiny}

During the 18 months of fieldwork, researchers followed the operation of health scrutiny in the eight authorities. Table 2 shows the type of scrutiny activity we observed which included examples of collaborative work, corporate support activity, and challenge. Previous research (Coleman, 2006; Coleman and Harrison, 2006) suggested that there has been more evidence of collaboration, as opposed to challenge, within the health scrutiny process and this tendency was confirmed across the eight case study sites. During our fieldwork we did not observe examples of campaigning scrutiny - a role which OSCs in general are least familiar with, (see Stoker et al., 2007, pp. 44, 48, and 59). However we did talk to HOSC members and officers who had experiences of a campaigning role and draw on their reported views in table 2 .

\section{Ways of working \\ Approach}

Ways of working varied between HOSCs, in relation to particular pieces of work and over time. Drawing on Snape et al. (2002, p. 51), who identified three broad approaches to the work of OSCs (traditional committee style, parliamentary select committee style and a new participatory model), we found that all the cases were still using the traditional local authority committee style for some of their work. This was also the case for parliamentary select style ways of working. Four of the cases could be described as having used the participatory (new) style of working during the research period and data suggested that it was emerging in at least one other case. However, all had or were using working groups, which in Snape et al.'s (2002) model belongs with the new style. This new style of working was most clearly identified with collaborative activities required of the HOSCs and commonly included input from health bodies, user groups and the public and was often seen where HOSCs had been able to set their own agendas for review. The advantages of this way of working were described by a councillor:

...it's a small group, and you can meet two or three times and...explore issues in much more depth...from a politician's point of view you're not constrained by the sort of political differences...they all tend to be cross-party - it's less political because it's a smaller group and I think it's also because people who go on the task groups volunteer, so its something that they're interested in.

Corporate scrutiny activities corresponded to the traditional parliamentary select committee 
style. The link between the challenge/campaign focus for scrutiny and scrutiny approach was less evident.

Agenda-setting and wider involvement

Different roles for scrutiny were linked with different processes of agenda-setting and involvement. For example, who was involved in setting the agenda and the actual review process? HOSCs in the sample had commonly conducted both chosen reviews and scrutinized statutory consultations (from the NHS). However, the consultation work evolving from the NHS (especially during 2006) often proved limiting and, in some cases, resulted in chosen review work being temporarily suspended (due to resource and time constraints). One councillor commented on the importance of being realistic in terms of a work programme:

There's far too much on it [work programme] and basically we need to start looking at what we want to do and basically thinking that we want to do a few things very well. What we don't want to do is do 15 things and feel that we're rushing through things and not doing them as well as we should do.
So we need to be quite firm and say, at the end of the year, we didn't do those things, but we produced three really good reports, and we feel that we achieved something by doing that.

While another councillor was frustrated over the lack of choice in scrutiny methods due to the type of scrutiny being undertaken during this period:

...part of my frustration is about we weren't scrutinizing like parliamentary select committees do because we were receiving best value reports and consultations and...you had to do a response within two days.

Wider involvement in reviews and agendasetting varied with way of working adopted and review topic. By late 2004, half (67) of authorities responding to a postal survey of local authorities (Coleman, 2005) stated that at least one person representing other organizations had been coopted onto the HOSC. These included patient and public involvement representatives, district councillors and representatives of individuals or local groups (for example older people and carers). Strong and Prosperous Communities

Table 2. Type of scrutiny, ways of working and associated advantages and disadvantages.

\begin{tabular}{ll}
\hline Type of scrutiny activity & $\begin{array}{l}\text { Ways of working (approach, } \\
\text { agenda-setting and wider involvement) }\end{array}$ \\
\hline $\begin{array}{l}\text { Collaboration } \\
\text { For example topics with a } \\
\text { cross-cutting or public health } \\
\text { heme or focusing on }\end{array}$ & $\begin{array}{l}\text { Linked to a working group approach } \\
\text { Closer involvement of NHS bodies in both } \\
\text { topic selections and processes of consultation } \\
\text { Inclusion of user-groups in scrutiny reviews } \\
\text { through consultation and involvement }\end{array}$
\end{tabular}

Corporate activity

For example supporting council's own role in developing health targets/ provision externally. Could feed into topics above

Policy development and reviews of council's own role in health promotion and provision

\section{Challenge}

For example likely to be those seen as threatening the quality and/or accessibility of local services

\section{Campaigning}

For example issues of current public concern
Linked to a parliamentary select committee approach

Strategic approach taken, supported by

knowledge of council's role and the corporate agenda and corporate performance assessment

Inclusion of taking evidence and expert witnesses

No one approach linked to challenge Agenda may be related to existing understanding of health inequalities or could be found in responding to statutory consultations or SDVs

May be councillor led—carried out ad hoc

No one approach linked to campaigning Agendas commonly stem from the public or whistle-blowers

May be councillor led-carried out $a d$ hoc
Advantages and disadvantages

Joint action plans

Joint resourcing of reviews/shared responsibility

Building or strengthening relationships with

health services providers and community

Reviews likely to reflect strongly user needs and views

In principle, more impact should be found from these processes. However, early intervention by scrutiny or NHS/council can prevent the emergence of issues. May limit critical friend challenge role of authority with other providers

Contribution to policy making in the council Improving management/administrative outcomes Raising the profile of health issues, and the role of the council in them, within the community May limit critical friend challenge within the authority

May open up the health agenda to the public and enhance democratic accountability

Might see NHS proposals effectively checked May disrupt collaborative activity and impact on productive relationships for the future

Might see more 'broad' citizen involvement Non-strategic ad hoc approach could be seen as limited way of scrutiny operating Higher degree of media interest 
(DCLG, 2006), proposed extending the use of co-options onto HOSCs. In our research, there was evidence of co-option being used and opportunities for public involvement were most commonly identified with reviews adopting challenging (for example NHS consultations) or anecdotally campaigning ways of working. NHS colleagues contributed to agenda-setting where collaborative working was identified and corporate activity often gathered information from key witnesses (council's executive, local authority officers, NHS representatives etc.). However, these were by no means mutually exclusive.

\section{Advantages and disadvantages}

The development of positive relationships with service providers has been facilitated by the use of collaborative approaches used by HOSCs. Across the eight sites, relationships had been built with NHS organizations and individuals within them and were considered constructive. More generally, however, challenge and campaigning roles have the potential to disrupt collaborative relationships (Coleman and Harrison, 2006). One local authority officer pointed out the potentially damaging nature of cultural differences between the organizations involved:

\section{I think culture, the cultural gap between the local democratic accountability of local authority, and the centralised political set up of the NHS is absolutely fundamental and crippling, potentially crippling.}

The government's increased emphasis on a more challenging approach to scrutiny needs to sit alongside the development of collaborative relationships. NHS organizations in many of the sites pointed to the positive nature of constructive challenge in making decisionmakers explain and justify their choices in public. This combination of collaboration and challenge may prove useful evidence to show other external organizations, which may ultimately fall under the gaze of scrutiny, about how scrutiny can work.

Table 2 highlights that tensions exist between the different types of health scrutiny, and their associated ways of working. It will be important for future external scrutiny committees (those scrutinizing health and other public service providers) to consider how and when they utilize the differing ways of working when undertaking scrutiny-they each have advantages and disadvantages. It will also be necessary to plan with councillors working on external scrutiny, executive councillors and partners around how to manage and plan for the different logics of interaction. This would help ensure the right services are commissioned while at the same time scrutiny would provide accountability around local service delivery.

\section{Conclusions}

The introduction and development of health scrutiny provides a helpful insight into the issues now faced by local authorities by the extension of external scrutiny. There are some clear lessons on how implementation can be assisted through improvements in internal process factors, the ones which individual authorities have most control over. The following emerged as important issues to consider in the future development of health scrutiny and the wider external scrutiny role:

- Provision of resourcing for committees, such as dedicated officer support, external research capacity, and the expansion of the use of co-option onto committees.

- Training for HOSC councillors and consideration of how to avoid overburdening the limited pool of councillors and committees when expanding the services scrutiny committees are expected to oversee. A particular training need, given the lack of experience generally in the campaign role of scrutiny, will be on the new 'councillor calls for action' and how these link into wider public and patient involvement processes for example for health scrutiny with the development of co-terminous LINks.

- Management of relationships with decisionmakers in both local authorities and external organizations to assist in embedding scrutiny in the culture of the different organizations involved and increasing awareness of the different aspects of the scrutiny role.

- Evaluation of new proposals for scrutiny of commissioning and the development of areabased committees to determine if this is the most appropriate focus for scrutiny.

Also included in the Local Government and Public Involvement in Health Act 2007 are proposals to hold local elections less frequently which may help facilitate committee working and enhance councillors' roles. Councillors will have a chance to become established in their roles and make use of knowledge and gained experience. Officers (and representatives from external organizations) will be able to support a group of councillors with whom they can build relationships in a more stable 
environment. However, the possible difficulty with all-out change will be potential loss of organizational memory and skills pointing again to the importance of establishing good officer support to assist in supporting new councillors in their scrutiny role.

Our assessment of health scrutiny shows the potential for non-executive councillors to make a valuable contribution to the governance arrangements of localities through opening up more organizations to democratic accountability, supporting executive decisionmaking and helping find new ways to engage the public in local decision-making, albeit through undertaking potentially different roles. This will be especially important in the context of the DCLG consultation 'Strengthening local democracy', which will look at giving councils more scope to scrutinize spending and decision making of local service providers (July-October 2009). What this research also demonstrates is that committees (whatever is being scrutinized) need to recognize the contradictions in their local contexts and resulting overarching approach to scrutiny. They will need to be able to identify the need for, and institutional responses to, campaigning, challenge, corporate and collaborative roles and adopt a portfolio of styles in which scrutiny is carried out to make sure it is appropriate, timely, inclusive and manageable for each review/ consultation undertaken.

\section{References}

Ashworth, R. and Snape, S. (2005), An overview of scrutiny. Local Government Studies, 30, 4, p. 538.

Bradshaw, D., Boyd, A., Coleman, A., Gains, F., Greasley, S. and Smith, L. (2005), Process, Progress and Making it Work: Health Overview and Scrutiny in England 2005 (CfPS, London).

CfPS (2006), The Good Scrutiny Guide: A Pocket Guide for Public Scrutineers, 2nd edn (London).

CfPS (2007), Scrutinizing for Health: Health Scrutiny Evaluative Research Project (London).

Coleman, A. (2003), Through the Looking Glass: The Emergence of Health Scrutiny (National Primary Care Research and Development Centre, Manchester).

Coleman, A. (2005), Health Under Scrutiny? (National Primary Care Research and Development Centre, Manchester).

Coleman, A. (2006), Health scrutiny, democracy and integration: part of the same jigsaw? Local Government Studies, 32, 2, pp. 123-138.

Coleman, A. (2007), Working jointly to scrutinize health? Journal of Integrated Care, 15, 5, pp. 2633.

Coleman, A. and Glendinning, C. (2004), Local authority scrutiny of health: making the views of the community count. Health Expectations, 7, 1, pp. 29-39.

Coleman, A. and Harrison, S. (2006), The Implementation of Local Authority Scrutiny of Primary Health Care: 2002-2005 (National Primary Care Research and Development Centre, Manchester).

DCLG (2006), Strong and Prosperous Communities, Cm 6939-1 (The Stationery Office, London).

DCLG (2008), Communities in Control: Real People, Real Power (London).

DCLG (2009), Consultation: Strengthening local democracy (www.communities.gov.uk/publications/ localgovernment/localdemocracyconsultation).

DETR (1998), Modern Local Government: In Touch with the People, Cm 4010 (The Stationery Office, London).

Department of Health (2003), Overview and Scrutiny of Health-Guidance (London).

Department of Health (2006a), Our Health, Our Care, Our Say: A New Direction for Community Services, Cm 6737 (London).

Department of Health (2006b), A Stronger Local Voice: A Framework for Creating a Stronger Local Voice in the Development of Health and Social Care Services (London).

Glasby, J. and Smith, J. (2003), Under the Microscope: Local Authority Scrutiny of Health (Health Services Management Centre, University of Birmingham).

Johnson, C., Coleman, A., Boyd, A., Bradshaw, D., Gains, F., Shacklady-Smith, A., Smith, L. and Greasley, S. (2007), Scrutinizing for Health: Health Scrutiny Evaluative Research Project: Final Report (University of Manchester).

Leach, S. (2005), Practice, Progress and Potential: An Assessment of the Local Government Overview and Scrutiny Function (CfPS, London).

Snape, S. and Dobbs, L. (2003), The scrutineer: the impact of overview and scrutiny on councillor roles. Public Policy and Administration, 18, pp. 4662.

Snape, S., Leach, S. and Copus, C. (2002), The Development of Overview and Scrutiny in Local Government (Office of Deputy Prime Minister, London).

Snape, S. and Taylor, F. (2001), A Hard Nut to Crack? Making Overview and Scrutiny Work (Local Government Association, London).

Stoker, G., Gains, F., Greasley, S., John, P. and Rao, N. (2007), The Outcomes and Impacts of the New Council Constitutions (CLG, London).

Stoker, G., Gains, F., Greasley, S., John, P., Rao, N. and Harding, A. (2004), Operating the New Council Constitutions in English Local Authorities: A Process Report (ODPM, London).

Sullivan, H. and Skelcher, C. (2003), Working Across Boundaries: Collaboration in Public Services (Palgrave Macmillan, Basingstoke). 